\title{
Introduction: The economics of the constitutional moment in Europe
}

\author{
Jean-Michel Josselin and
}

Alain Marciano

\section{INTRODUCTION}

Europe provides a fascinating and far-reaching field of investigation for economists. Agriculture, industrial policy, transport and so on, are many subjects that are thoroughly dealt with. But what about law? The provision and the use of law cannot avoid strategic behaviour by individuals or groups of interest. The creation and development of constitutional frameworks cannot be dissociated from rent-seeking. Judges are granted the right of juris dictio and as such they have a tremendous power that they can use to further their own private interest. At the same time, they must deal with possible strategic behaviour by the plaintiffs and must find rational criteria to provide sound decisions. Economics is particularly well suited for analysing such topics as private or public law. Public choice and constitutional political economy (Buchanan, 1990) are relevant approaches which consist of using economic tools to understand the choice of rules instead of simply studying individual or collective behaviour within an exogenously given set of rules. When this set becomes endogenous, the scope widens to comprehend constitution-making processes and the various ways of juris dictio by judges. Public choice, constitutional political economy and law and economics are close enough perspectives to all belong to the new political economy. Public choice mainly focuses on political mechanisms (Mercuro and Medema, 1997, p. 84). The emphasis can also fruitfully shift from the politician to the judge, from the vote to the court decision. A law and economics perspective has to focus on the mechanisms through which laws are passed and on the way their interpretation and efficiency evolve. In this matter, economics and the law are so intertwined that any attempt to provide compartmentalized analyses cannot but fail to reach its goal, if the latter is to explain things as they are or should be. Moreover, law and economics must build on both political economy and economic analysis. 
It brings us back to the founding fathers of the discipline, Hume and Smith, but also rests on the more recent theoretical developments of the agency theory or the economics of information and collective decision making.

The chapters in this volume all belong to this tradition, which consists of analysing legal issues in a new political economy perspective. They show, through diverse and sometimes contrasting views, strong opinions or preferences as to what the ius commune will be or should be in the future. Contributors were asked to analyse the harmonization of law that results from the European integration process. The chapters then compare the respective vices and virtues of competition, a decentralized process of producing European common rules of law, and of harmonization, a centralized mechanism of creation of law. The book comprises three parts. First, the comparison between competition and harmonization is addressed from a general and theoretical perspective (Jan Smits, Roger Van den Bergh, Sophie Harnay and Isabelle Vigouroux, Anthony Ogus). Second, applied issues are investigated: criminal law (Nuno Garoupa), the European directives about product liability and product safety (Michael Faure), public utilities (Thierry Garcia and Xavier Peraldi), interregional co-operation (Sylvie Graziani and Michel Rombaldi), professional skills (Jean-Baptisite Calendini and Christophe Storaï). Rather than summarizing the previous debates, the third part builds on what we already know about Europe in order to shed some light on its future. As will be clear when reading the first two parts, the European institutions are still the object of the game, rather than merely its exogenous framework. The various players (individuals, regional or national jurisdictions, groups of interest) still have to define and stabilize the setting in which they will try to optimize the payoffs resulting from their interacting strategies. In this respect, harmonization is far from being the only way forward, as is advocated by Bruno Frey. Moreover, since the number of players is not yet fixed, the relevance and efficiency of enlargement must be at the heart of the agenda for future reforms (Dieter Schmidtchen, Alexander Neunzig and Hans-Jörg Schmidt-Trenz). At the same time, whenever collective decisions use institutions whose power goes beyond that of competitive protective agencies, the question must be raised of the control of the state. Constitutional safeguards must guarantee rational and efficient coercion (Jürgen Backhaus).

In the discussion that follows, we place these contributions in the perspective of the constitutional moment in Europe, an issue to which all the chapters in this volume are connected. The time is indeed clearly right for this constitutional moment. The European Union now has a past, a history of its own. Even if Europe is going to face some difficulties in going backwards because of a possible 'ratchet effect' (Vibert, 1995, p. 154), no institutional option is yet closed and new directions can still be taken. Mistakes and achievements are lessons for the future. But if a common past does have advantages, it also 
brings about drawbacks that further justify the constitutional moment. The sedimentation of institutions, the absence of constituent assemblies before the redaction of the different treaties and the democratic deficit all indicate the urgent need for reforms.

\section{LETTING RULES SPONTANEOUSLY EVOLVE}

There are many ways of creating or reaching a harmonized system of rules. In this respect, and to use broad categories, the evolutionist and contractual approaches still compete. Economists are of course not the only ones debating on this subject. Particularly when it comes to discussing the future of Europe, political scientists also find a split (European Journal of Public Policy, 1999). In fact, this is an old debate, dating back to arguments between Hobbes and common lawyers. While Hobbesian constructivism relies on rational calculus, common law jurists like Coke develop the evolutionist perspective of accumulated experience as the soundest possible basis for efficient judgements. Beyond that, and beyond the unbridgeable gap between the two underlying conceptions of human nature, the fundamental point is the way in which the publicity of the law is built. Coke and others were confident of a spontaneous process. On the other hand, Hobbes pleaded for contractual publicity. Much more recently, this argument has also been emphasized by lawyers like Kelsen and by philosophers like Rawls. In the field of economics, the concept of publicity of law relates to the different ways of building the common knowledge of the corresponding rules (Josselin and Marciano, 1995). Should we use accumulated experiences to build it? Is it realistic in the context of already existing nations? A great number of small and continuous interactions can indeed lead to this common knowledge. There remains to assess it with regard to the convocation of a constituent assembly whose purpose would be to explicitly build common knowledge instead of letting it emerge. In this section, we first analyse the theoretical background on which the evolutionist perspective rests. We then move on to the limits of this perspective, in general terms as well as in the field of harmonization.

\section{Evolutionism, Spontaneous Order and Common Knowledge}

Evolutionism as a theory of social and cultural evolution is mostly based, as Jan Smits (Chapter 2) and Anthony Ogus (Chapter 3) remind us, on the Hayekian argumentation in favour of spontaneous order. The instances of successful regimes of spontaneous law all have in common that they are systems of customary law. The English common law is usually considered as grounded on customs (see Hogue, 1966, pp. 190-200). It is then also and quite 
often considered as a unique example of how and how far a process of spontaneously selected rules can work.

In a constitutional political economy perspective where the framework for decisions is endogenous, this brings about a most important debate. Common law advocates do not of course rely on Hobbesian rational calculus to ground their position. The reference is rather that of the spontaneous order tradition, revived by the founding fathers of classical political economy during the Scottish Enlightenment. Repeated interactions between individuals lead to the spontaneous emergence of historical precedents; tacit norms or conventions then appear and next turn into more or less formalized rules. The latter do not result from the will and design of human beings but are rather the consequence of their actions: no one has explicitly decided to create them. However, everyone has decided to use them as guidelines and it is publicly known that everyone has done so. It then appears that these conventions are common knowledge rules. Therefore, no explicit agreement or communication about the sense of rules is needed. Coordination of actions, without reference to intentions, is a sufficient condition for successful communication (Josselin and Marciano, 1999b). In particular, it defines the legal culture of the group in which the interactions develop. From place to place, a phenomenon of imitation ensures the spreading or selection of the rules followed by successful groups. As noted by Hayek, 'this process of selection follows in many respects the same pattern as biological evolution . . . Cultural evolution, because it also rests on a sort of natural selection looks very much like biological evolution' (1988, p. 292). Hayek's enthusiasm as to the way common law evolved neglects the role that private interests have played in the evolution of law in England (Hogue, 1966). His argument, however, refers to organizational efficiency. Others have shared his enthusiasm concerning common law, arguing that economic efficiency is also at the rendezvous.

Theoretical insights provided by evolutionary biology have frequently been used and they are supposed to illuminate the debates about social and cultural evolution. In this perspective the selected rules are supposed to be the most efficient ones; in the words of biology only the fittest rules survive. A related issue is that normative questions are ruled out since efficiency is guaranteed by the process of natural selection. These points are elaborated in Jan Smits' analysis of European private law (Chapter 2). He thus considers that, beside the difficulties 'to predict to what extent the different areas of private law will evolve toward some uniform system', one can nonetheless argue that competition between different legal orders would promote efficiency in allowing the selection of the 'best available rules'. Smits also notes that it is 'inevitable' that 'not all the present social guarantees in the European legal systems (namely those that guarantee more than the European minimum standards) will be kept intact'. But '[w]orries about some mentality being strangled in 
this process are then not relevant anymore: that would be the irreversible consequence of an internal market coming about'.

\section{Spontaneous Order and Evolutionary Background}

One would not be surprised to find a reference to Darwin, as in Jan Smits' chapter, as a theoretical background for an evolutionary approach to the selection of rules. An explicit reference to Darwin would indeed help clarify the meaning of rightness and efficiency in this context. However, Darwin is not a frequent reference in theories of social evolution. In particular, his name rarely appears in Hayek's books and papers.

What is usually considered as the Darwinian theory of social evolution is due to Herbert Spencer rather than to Charles Darwin himself. For instance, the frequently used expression 'survival of the fittest' is proposed by Spencer and not by Darwin, who only used it in later editions of The Origin of Species and did not use it in The Descent of Man. Moreover, Darwin insists on the decisive role of moral sentiments or, more precisely, sympathy, which are concepts he explicitly borrows from Hume and Smith (Marciano and Pélissier, 2000).

The consequences for a theory of social evolution are twofold. First, because the process of natural selection in human societies rests on sympathy, the normative content of selected rules is assured (Josselin and Marciano, 2001). In other words, if we follow a Darwinian line of reasoning, rules could not be selected for their efficiency but for their capacity to generate a social order in which relationships are based on sympathy. This leads us to one of the limits of a spontaneous order process: we cannot be sure that evolution is just. Hayek even claims that 'evolution cannot be just' (1988, p. 20) which means that rightness must be found in the evolution process itself rather than in its outcome. Secondly, there is no certainty that evolution could select the most efficient rules. Among others, Brennan and Buchanan remark that

social conventions that emerge historically and take on the status of 'unwritten rule' do not necessarily produce the best conceivable pattern of outcomes. Some modern social analysts (notably Hayek and his followers) display an apparent faith in the forces of social and cultural 'evolution' to generate efficient rules. There seems to be no reason to predict that these forces will always ensure the selection of the best rules. (1985, pp. 9-10)

Nozick gives a discerning illustration of this proposition in pointing out that chance can be a means of selecting a rule (1974, chap. 6). A convention might be institutionalized without any 'calculus of consent'. No one can be sure that chance has any bias towards efficiency. 


\section{The Spatial Limits of Evolutionary Harmonization: Legal Culture and Induction}

An evolutionist view on the European legal order rests on the possible hybridisation of the different legal systems and thus assumes the possibility of 'legal transplants' from one country to another. These transplants are made possible when a rule is susceptible to being used, and then adapted, in different legal regimes. A first problem consists in prohibitive costs of adaptation. A second and more crucial point is made by Legrand in his radical criticism of legal transplants. He argues that, because the specific 'legal culture', defined as 'those historically conditioned, deeply rooted attitudes of law and about the proper structure and operation of a legal system that are at large in the society' (1996, p. 52, quoted by Ogus in this volume), attached to existing legal systems, transplants are impossible and then the convergence of the legal regimes in precluded. His argumentation rests on the link between 'cultural heterogeneity' and 'the situated, local properties of knowledge' (1997, p. 123, ibid.). Legrand's argument is extreme. In a weaker form, it nonetheless suggests the spatial limits of competition. The question concerns the possible generalization of rules born in a specific context and dedicated to specific recurrent problems. Are these rules likely to become applicable beyond the initial boundaries within which they emerged, or to become relevant to instances that were not concerned in the first place? Among the different elements of a legal culture, labour legislation is one of the most important. In this domain of law, as noted by Jean-Baptiste Calendini and Christophe Storaï in Chapter 8, the probable tensions between the different national traditions could be an obstacle to the spontaneous harmonization of law. The generalization, or transplantation, of rules has to solve a problem of induction. A newcomer entering a game may face induction problems because of his inability to know positively the meaning another person gives to the rules or to infer this meaning from the observation of her behaviour (Josselin and Marciano, 1995, 1999b). Therefore, evolutionism has to face problems of induction.

However, one should not too quickly conclude that transplants are impossible. The existence of a problem of induction 'only' stresses that a transplanted rule will never be the same again, both at home and where it is transplanted. What is then important is the way in which the different rules are made accessible. Therefore, the existence of a legal culture does not imply that transplants are impossible. It affects the nature of the process through which rules are likely to be transferred from one legal regime to another one. This could be an argument in favour of a European social contract whereby the common knowledge of rules would be explicitly constructed. One may conceive that repeated interactions between individuals do lead to the spontaneous emergence of commonly accepted rules. One may even acknowledge 
that such rules are efficient, at least in organizational terms. We should certainly be more cautious when it comes to making legal culture interact in order to breed a commune ley. The dynamics of legal systems remain a largely unknown territory, though Kelsen warned us quite a long time ago now that this is a major key for understanding law.

A purely evolutionist conception of harmonization has thus to deal with problems of induction which limit the efficiency of spontaneously selected rules. A covenant or a constitutional contract is a solution to the problem of induction. The underlying argument of this chapter is then that Europe cannot do without a social contract whose many possible forms must be discussed. For obvious reasons, the unitary mode of organization has never received great attention while federalism has been considered as a possible direction from early on. The choice between a competitive and a centralized federalism grounds the constitutional moment for Europe.

\section{THE REGULATION OF COMPETITION BETWEEN LEGAL ORDERS}

The Tiebout model is the soundest possible basis on which to ground federalism, even if the specificity of the European situation calls for some scepticism when it comes to applying theoretical principles of competition. Furthermore, the Tiebout perspective cannot comprehend all the aspects of the provision of public goods. In particular, the legal culture may display some characteristics of monopoly, which requires a careful design of the juridical institutions.

\section{European Federalism and the Tiebout Model}

Building on the American experience may not be as straightforward as it could seem at first glance. There are two reasons for that. First, caution is necessary because the USA has a very specific form of government; Australia or Canada could have also been designed as possible models. Furthermore, American scholars themselves do not recognize Europe as an illustration of their own federal structure. For instance, Buchanan writes: 'Europe, as observed does not correspond to the theorists' model for political federalism, and the course of history remains open as to whether or not any approximation to this model will ultimately be realised' (1996, p. 253). Buchanan's statement suggests a discussion about the capacity for the European Union to follow the path of the USA and, more generally, reveals scepticism as to the ability of governments to put good (at least Pareto-improving) ideas into practice. The gap between the institutional structures in America and in Europe stems from the differences in the respective situations of the US nation and of the European nations. 
There is, thus, a second reason for being cautious: federating a nation is quite different from federating existing countries. The harmonization process in Europe is constrained by the necessity to take into consideration the diversity of ideas, cultures and policies that at the same time form the 'strength of Europe'; a variety without which Europe will 'lose its raison d'être and will lose its economic and political role' (Frey, this volume).

The Tiebout model provides a useful, even if partial, background for the European federalism. The use of the 'market metaphor' (Donahue, 1997) illuminates the workings of the legal markets. In this volume, Faure (Chapter 7), van den Bergh (Chapter 1) and Garoupa (Chapter 6) show that Europe could draw advantageous lessons from the economic theory of competition between jurisdictions. The argument is that federalism may be structured through competition between jurisdictions. The idea is to build a non-cooperative but at the same time non-conflicting game between local governments. The latter should be interpreted as the smallest functional units (Backhaus, 1997a) to which the provision of public goods is assigned.

Competition among local governments is expected to limit possible predation. It provides incentives to attract mobile factors and to reduce transaction costs on markets. The Schengen agreement has created an area of free circulation; it is thus an element in favour of a competitive model of federalism. However, beside this institutional prerequisite and from a practical perspective, free circulation requires for instance that the different degrees and qualification between nations be harmonized. This is a major contribution to the creation of a European harmonized labour market. These are two necessary conditions that need to be fulfilled in order to ensure the mobility of the labour factor. Jean-Baptiste Calendini and Christophe Storaï discuss this issue in Chapter 8. The respective historical backgrounds of the European labour markets provide many barriers to the creation of a unified market. JeanBaptiste Calendini and Christophe Storai insist on the link between the harmonization of qualifications and that of the labour market. They stress the difficulties that attempts at uniformity may face. The Commission did publish a white paper on teaching and learning, which presented the conditions required for a uniform norm for the recognition of 'skills'. But, the adoption of a common, consensual, definition of what 'qualification' means seems to be a strong requirement before going towards more flexibility on the labour market.

In counterpart, Nuno Garoupa in Chapter 6 shows that there is at least one type of skill that is general enough not to be bound by historical conditions and the features of national markets. These are the capacities individuals acquire and use on illegal markets. The only barriers that are likely to constrain the emergence of a European criminal market are the national frontiers. Once the limits are removed, the criminals face lower transaction costs and their activ- 
ity is likely to increase. As these cases show, the framework of this competition must not let the players fall into a prisoners' dilemma. The government at the highest level must see to it. However, the process has some limits, which requires that the debate goes beyond the Tiebout model.

\section{Going Beyond the Tiebout Model}

As is vigorously stressed by Musgrave (1997) and Donahue (1997), Tiebout assignments cannot be so easily generalized since they largely build on a metaphor. Competition on the market for goods cannot be straightforwardly extended to jurisdictional competition. In particular, this competition may take place in a conflicting setting, just as in markets for goods the outcome may be that of a price war. Generalized strategic behaviour of local governments generates a race to the bottom. It can myopically be seen as beneficial by some jurisdictions, but others will soon be lured into grabbing short-term benefits. Non-optimal provision of public services will ensue. Moreover, voters themselves can display detrimental strategic behaviours. For instance, provision of law at lower levels of government may induce legal externalities. Corporate law is an example of how such externalities help citizens of a given jurisdiction catch the benefits of a law and transfer the cost onto the residents of other jurisdictions (Rose-Ackerman, 1992).

European rules should thus limit the scope for a race to the bottom. In other words, there are fields in which centralization and EC law could have positive effects. Corporate law, for instance, may be cited as one of these areas in which EC law has an important role to play. It is also at the core of Chapter 1 by Roger van den Bergh in this volume. Company laws in Europe are constructed to provide harmonization (Carney, 1997). To put it in other words, 'competition and harmonization may be complements, rather than substitutes' (van den Bergh, this volume). The Treaty of Rome, with articles 54 and 58, acknowledges that federating nations require the creation, not to say the construction, of a common market. During the process, rent-seeking may of course thrive. Competition on the market for corporate law would certainly weaken rent extraction, as is the case in the USA. However, the American common market spontaneously emerged along with the fledgling nation. This early and competitive creation produces fewer regulations and probably more efficiency.

The race-to-the-bottom argument should not be overemphasized since, as noted by Scott, 'there is almost no evidence that, under competition, the feared race to the bottom is more that theoretical' (2000, p. 204). Faure (Chapter 7) confirms that judgement by showing that this argument is not strong enough to justify a centralized provision of law in the case of product liability.

For all its insights, the Tiebout model cannot comprehend all the aspects of 
the provision of public services. First, Samuelsonian public goods cannot be dealt with by using exclusion mechanisms and preference revelation through mobility. If law is a pure public good then the market metaphor is quite useless. The American Federalists developed this argument when they advocated the shift from the Articles of Confederation to the 1789 constitution. Secondly, the Tiebout setting cannot comprehend spillovers. Indeed,

the Tiebout argument of competition between local communities obviously works only if the problem to be regulated is indeed merely local. Once it is established that the problem to be regulated has a transboundary character, there may be an economics of scale argument to shift powers to a higher legal order that has competence to deal with the externality over a larger territory. (Faure, Chapter 7 this volume).

The centralized provision of law is required because of the transboundary effect of the regulated activities. Environment has repeatedly been presented as one of the type of activities in which centralization is required in order to avoid the cross-border effects of pollution. It is nonetheless important to remark that central authorities have many instruments at their disposal. The choice of the relevant legal tool must nonetheless be a cautious one. Can the same argument be replicated to different legal issues? In this volume, Michael Faure examines the case of product liability and product safety. His conclusion is: "the mere fact that different states would hold different preferences with respect to product liability and product safety and that therefore different regimes would exist, can as such hardly be considered as an argument for centralisation as long as states are not capable of externalising harm to victims in third countries'.

\section{Legal Culture: Natural Monopoly and Competition}

One of the main assumptions of the Tiebout model is the perfect elasticity of the supply of jurisdictions. Among others, Donahue (1997) and Musgrave (1997) argue that this is not historically relevant, at least in the American case. In theoretical terms, rather than being anonymous and competitive suppliers, local governments display strategic behaviour in a non-cooperative game setting (Inman and Rubinfeld, 1996, 1997a and b).

Citizens themselves may not have uniform incentives to move from one jurisdiction to another. The level of the corresponding transaction costs may depend on their productivity or on their wealth. This may reinforce the negative aspects of the provision of public goods by local governments. Furthermore, when considering legal competition, the elasticity of location relative to the legal rules may be much closer to zero than for any other good. There is a 'portfolio effect' (Donahue, 1997) in this matter. As Michael Faure argues when considering this point, not only 'people may stay even if the 
(legal) regime does not suit their need optimally' (this volume) but also 'the legal regime may not be decisive [because] . . . job location and residence are that important in reality, there is often little left for people to choose' (Faure, ibid.; compare also Rose-Ackerman, 1992).

In Chapter 3 Anthony Ogus offers an original explanation of the link between legal culture and the impossible convergence of legal systems. He tells us that legal culture is a natural monopoly. He then writes that '[a] predictable consequence is that practising lawyers will exploit the situation, generating rents for themselves by, for example, promoting formalism and complexities and other features which enhance their income'. Such barriers to entry increase problems of induction, much to the advantage of lawyers who cannot but profit from the corresponding asymmetries of information. Industrial economics teaches us the need to regulate activities in situations characterized by natural monopolies in order to reach an optimal level of production. However, here lies a major problem, namely the existence of pressure groups likely to influence the regulation process. The rents created by regulation are then likely to be captured by the rent-seekers. This is typically what happens on the legal market.

Ogus notes that regulatory constraints are difficult to use and to implement 'because lawyers constitute a powerful pressure group, adept at influencing the law-making machinery'. This is the case as long as we consider competition within the field. To this first problem, a second one can be added, namely, as Tullock and Demsetz have argued, competition for the field itself. Their view of political competition as a franchise bidding for political monopoly can be usefully applied and further substantiated in order to highlight and discuss basic aspects of the European integration process. The provision of law is not organized as an ongoing market process. Instead of playing a competitive game among legal systems, suppliers of law may compete in order to reach monopoly power. Is it a matter of artificial barriers to entry, for instance through procedures that exacerbate problems of induction and hence asymmetries of information? Is it a matter of economics of scale in the provision of law?

The argument implies the possible competition between European and national judges. Roger van den Bergh, in Chapter 1, considers this situation and notes that 'the European legislator engages in competition with the national legislators rather than eliminate it by means of harmonization'. This is indeed competition for the field. In the same vein, Sophie Harney and Isabelle Vigouroux in Chapter 4 develop a model that describes European integration as the result of a process of competition between national and European judges. The model shows that competition does promote legal innovation. What could be considered as a positive effect also has the negative consequence of leading to judicial activism and the related judicial empowerment (to use the words of 
Joseph Weiler). In this perspective, national judges have a vested interest in promoting the rules enacted by the European judges. Thus, competition increases centralization and harmonization. Sophie Harnay and Isabelle Vigouroux propose a conclusion that is similar to the one given by Anthony Ogus: we can expect an increase in the role of lawyers and judges. However, beside the virtues of the spontaneous evolution of law, Harnay and Vigouroux insist on the crucial importance of the institutional setting in which competition takes place or should take place. And some of these institutions may sometimes be distortional.

\section{A POSITIVE ASSESSMENT OF EUROPEAN FEDERALISM}

One cannot but deplore, as Roger Van den Bergh puts it, 'the lack of an appropriate European constitutional framework' (this volume). The agency theory provides an insightful means of analysing the strategic behaviours of the central institutions. A positive assessment of the present European constitution is then possible.

\section{The Inappropriateness of the Institutional Framework}

The inappropriateness of the European institutions clearly appears when one tries to list the impressive number of pressure groups influencing the provision of law and public decision making in Brussels. To say that Europe is a rentseeking society is largely a euphemism. These strategic behaviours are made possible by a specific constitutional structure. There are of course many explanations for the existence of those pressure groups. One of them fits the microeconomic approach and the political economy perspective. European institutions are designed through, and evolve into, an agency framework whose incompleteness paves the way for inefficiency and rent-seeking. Constitutions can fruitfully be formalized as agency contracts (Anderson and Hill, 1986; Wagner, 1988, 1993). In this setting, economic models of agency help understand the nature of authority and power (Aghion and Tirole, 1997), administrative law or Verwaltungsrecht (Josselin and Marciano, 1997, 1999a). Usually, the focus is put on the efficiency of the agency contract, and the role of incentive or control mechanisms. We rather stress here the instability of the contract as a consequence of its incompleteness.

Incompleteness usually relates to the argument according to which the payoffs associated with the projects are unknown. What we emphasize here is the incompleteness of the set of projects itself. First, the number of projects may be unknown. Second, the contracting parties may not be able to clearly delineate what in a given project belongs to the field of competence of the 
principal. The agent then has some power to define his own domain of choice. He may then use this power strategically in order to displace his principal (Josselin and Marciano, 2000). When the agency contract is incomplete, conflicts inevitably arise between existing national laws and the emerging European law. Under article 164 EEC, the European Court of Justice settles these tensions and thereby completes the contract. The doctrines of direct effect (Van Gend \& Loos, 1963) and supremacy (Costa v. ENEL, 1964) serve this purpose.

The European Court of Justice thus plays a major role in the evolution towards a constitutional status. In this respect, the decision made in the Van Gend and Loos case (Van Gend \& Loos v. Nederlandse Administratie der Berlastingen, case 26/62, 1963, E.C.R. 1) is fundamental. It acknowledges the co-existence of two levels of principalship: the Community is a new legal order of international law ... the subjects of which comprise not only the Member States, but also their nationals'. The ensuing shift in principalship is only partial. The status of international organization no longer fits the situation since member states lose part of their prerogatives. They now share principalship with their nationals and the nationals of the other states. The European Court of Justice displays a judicial activism that leads to the constitutionalization of the treaties: The Treaty of Rome is defined as the 'basic constitutional charter' (Parti écologiste 'Les Verts' v. European Parliament, case 294/83, 1986, E.C.R. 1339). On the other hand, Europe does not for all that become a federation since two levels of principalship remain, thus partly preserving the states' rights that characterize a confederate organization; Holcombe (1991) shows in the American case how states can directly control their agent in a confederation. In the European case, the Court acts as a constituent power.

\section{The Constitutional Status of Europe}

Europe has no definite and precise constitutional status. Some scholars have stressed that Europe is 'unique in its structure' (Sbraggia, 1992); others have considered that the European constitution is 'hybrid' (Koslowsky, 1999). The reason is that Europe stands in the middle of the ford, between an international legal order and a constitutional order.

The first stages of the European integration process cannot be interpreted as directed, at least avowedly, by the aim of building a new state that would rest on a higher constitutional norm. Europe should rather be considered, at its origin, as an 'international legal order' (see for instance Schilling, 1996, or Weiler and Halpern, 1996). The regime builds upon a number of Treaties (ECSC, EEC, EURATOM) forming a compact that defines the European legal order. Since no constituent power intentionally designed it, this set of treaties cannot be considered as a constitution in itself. The process is that of 
intergovernmental conferences whose conclusions are ratified by national legislatures, the latter having no constituent power in this respect. The decision made in 1957 in the Dineke Algera et al. v. Common Assembly of the European Coal and Steel Community (joint cases 7/56 and 3-7/57, opinion of Mr Advocate General Lagrange, ECR, 69: 82) is a perfect instance of such a situation.

In an international legal order, member states are in the position of principals while the institutions of the European Community are their agents. Existing and constituted states do contract and they delegate precise and enumerated tasks to the central institutions. The agency contract thus defines the respective prerogatives of the two sides. On the one hand, the laws governing international treaties bound the actions of the EC institutions; there is no way for them to eradicate their subordination to the principals. On the other hand, the principals do intend to retain formal authority. Of course, the delegated prerogatives are in practice far from stated once and for all. But the tasks delegated to the agents are controlled by the principals who may change their extent according to the resolutions they manage to reach. Furthermore, following the decision processes of an international regime, changes in the prerogatives of the agents result from bargaining and negotiation between the principals who remain the ultimate enforcers. There is indeed no enforcement mechanism outside their own collective will. This obviously requires that a collective will exist, which is far from straightforward since the decisionmaking process is based on the rule of unanimity while each state keeps a veto power. A positive account of the difficulties to reach agreements in this setting is given by the failure of the first attempt in 1952 to finalize a treaty establishing a European Community of Defence.

Under this intergovernmental regime, there is no locus for a final authority external to the principals. The international or central institutions are not granted any compelling prerogatives. More specifically, there is no central judicial power. The European Court of Justice mainly verifies that the secondary law (legislation proposed by the Commission and enacted by the Council of Ministers and Parliament) fits the frame of the Treaty of Rome under the control of the member states. How far and how quickly will the Court gain more power? The case of the USA and the Supreme Court of Justice gives evidence of a trend towards centralized federalism. In the absence of a formal European constitution, the ECJ may have even more latitude to lead a movement towards a federal constitutional status. What will remain of the principalship of member states? Adding to that the fact that the Treaty of Rome allows majority voting with article 189, it happens that from the beginning Europe displays some attributes of a fledgling supranational state.

To move from an intergovernmental structure to a supranational regime 
requires a change in the agency relationship and a shift in principalship. The agency contract is now meant to take place between the citizens themselves, for instance through a constituent assembly, and the supranational level. Principalship thus moves from the states to the citizens. In theory, the people are now considered as the source of the power and decisions at the federal level should no longer result from bargaining processes between the member states. The federal level is a central and final level of authority, an agent supposedly controlled by the citizens-principals. In the wake of this shift in principalship, member states lose many of their previous prerogatives, among which their power of veto. The rule of unanimity is relaxed and replaced by majority rules of decision. Whereas under an intergovernmental regime negotiation is the way through which decisions are reached and prerogatives assigned to the central level, the power of the federal institutions is now explicitly stated in a constitution. This constitutional assignment is ultimately enforced by the guardian of guardians, namely the federal court of justice. The latter also checks the behaviour of the other parts of governments and contributes to the balance of powers.

A real shift towards a federation would have required that a constituent assembly defined the prerogatives of the central government. This is obviously not the case: with two levels of principalship, Europe is neither a confederate nor a federal structure. This unsettled situation may require a constitutional moment.

\section{SUGGESTIONS FOR THE FUTURE CONSTITUTIONAL MOMENT}

The preceding discussion has revealed the need for constitutional safeguards in order to control possible strategic behaviour as well as the necessity to go beyond the Tiebout model in order to define a framework for the European federation. Subsidiarity then appears as a key concept. However, one should not take the virtues of federalism for granted. Administrative law appears as a necessary and relevant way to control the state.

\section{A Democratic and Competitive Federalism}

It is not at all sure whether all the opportunities offered by the concept of subsidiarity have been explored in theory and in practice. It may require much more attention and application than is often given, with a few exceptions such as van den Bergh's paper (1994). The subsidiarity principle (Article 3B, Maastricht Treaty) can limit the set of activities of the EC institutions since it contradicts the doctrine of the supremacy of the European Community law. 
Applied to environmental policies in Europe for instance (Backhaus, 1997b; van den Bergh, Faure and Lefevere, 1995), it appears to be a very effective instrument of analysis and reform. The economic interpretation provided by Backhaus (1997a, 1999), following the legacy of Wolff, gives a framework in which the various forms of federalism can be assessed. Constrained optimization of the choice of institutional structures requires that tasks should be delegated to the smallest functional units. Once this general principle is set, it can be implemented in three ways.

Lateral subsidiarity relates to institutions of the same rank cooperating in order to solve a given problem; confederations are mainly founded on this form of cooperation. That was the initial setting in which the early European Community worked. It still uses it when one follows the interpretation of the intergovernmental thesis. Upwards subsidiarity provides a means of finding solutions with institutions of higher level, as is the case with centralized federalism. This is in many respects the case with the USA, and Europe may tend towards this solution as well. However, the USA now seem to engage in a process of devolution (Tannenwald, 1998) that shows many characteristics of downwards subsidiarity, whereby communities of lower level are more likely to efficiently handle many problems. Europe may follow this path, both in spatial and functional terms.

A promising direction of research and practical implementation indeed relates to the spatial and downwards reorganization of governments. Since the devolution process in a unitary state like Great Britain, and since the formal acknowledgement of subsidiarity in the Maastricht treaty, one could claim that nations will never be the same again. Economic theory reaches a similar conclusion when it assesses the rationale for mergers and dissolution that constantly reshape countries. Wittman (1991) and Blum and Dudley (1991) have provided path-finding models that help understand why nations rationally form or break-up. Further models by Alesina and Spolaore (1997) or Bolton and Roland (1997) follow the same idea. This way of conducting an economic analysis of highly emotional subjects is fascinating since it reveals the rationality that grounds political decisions. This approach can of course be applied to possible reforms towards downwards subsidiarity in Europe. In this respect, decentralization provides strong incentives for governments to act efficiently (Salmon, 1987, 2000). Underlying this process is the idea of the constitutional liability of regions. Three arguments may provide a rationale for it. The first one rests on a classical political economy perspective. Hume shows how moral sentiments are scarce feelings usually restricted to areas of nearness. What we could label the 'topology of Humean sympathy' defines territories ruled by local norms (Josselin and Marciano, 1999b). The second argument takes the form of a dilemma. How to get both the efficiency of local public decisions in some matters and at the same time profit from the stabilizing coinsurance 
provide by national policies? An efficient status of regions in Europe rests on 'a trade-off between allocative efficiency, fostered by regional differentiation and financial responsibility, and risk-sharing efficiency, achieved through mutual insurance permitted by the adoption of uniform rules' (Drèze, 1993, p. 277). Of course, the increasing importance of regions comes from the decline of the nations. It is also possible to consider it as a consequence of the decline of the Welfare State, as is argued by Sylvie Graziani and Michel Rombaldi. In this respect, new forms of governance, based on interregional cooperation, could be required to correct possible disparities among the regions of Europe. Sylvie Graziani and Michel Rombaldi (Chapter 9) remind us that the Commission insisted on the need to consider interregional cooperation as a mean of harmonizing the European territory: 'the interregional cooperation programs have become indissociable from the European construction efforts'. The third argument rests on heterogeneous spatial clubs. The integration of regions showing quite specific preferences inside unitary states may be very costly. From an efficiency perspective, the constitutional enterprise is indeed spatially constrained (Josselin and Marciano, 1999c). This may provide a strong incentive towards federalism.

Another direction of research considers the functional dimension of federalism (Casella and Frey, 1992). Markets cannot instantly create geographical jurisdictions. Their supply is therefore relatively inelastic. This simple fact reinforces the necessity of organizing competition, in such a way as to provide the adequate institutional framework we referred to earlier. If we add to this the imperfect mobility of individuals, then jurisdictions may advantageously compete on a functional rather than territorial basis. They would geographically overlap and provide a strong basis for a directly democratic and federal Europe. The corresponding concept of FOCJ (Frey and Eichenberger, 1996, 1997) emphasizes the efficiency attached to downwards subsidiarity. It also implies a variety of organizational forms, practices and institutions regulated by competition and direct democracy. And this brings us to the core of the argument presented by Bruno Frey: how to harmonize without losing the benefits associated with democratic and competitive governmental institutions (Chapter 10).

Competition and democracy may be the keywords that would guide any trend towards a larger Europe, that is, enlargement in scope and functions, but also in terms of the countries involved in the process. Competition in itself can lead to unjust outcomes, as we have seen before. Democracy is then the necessary complement to the spontaneous and competitive evolutionism described by Jan Smits. At the same time, the upper framework of the constitution is recognized as something much more important. This is the case in positive terms: the constitution is the necessary setting for organizing efficient competition, as Roger Van den Bergh shows. This is also the case in a normative 
approach. Sylvie Graziani and Michel Rombaldi strongly advocate the regulation of competition.

The issue of enlargement thus crystallizes all the questions raised by the future of Europe: Which competition? Which democracy? Which constitution? The analysis by Dieter Schmidtchen, Alexander Neunzig and Hans-Jörg Schmidt-Trenz (Chapter 11) gives a clear view of the problem at stake. An augmentation in the number of the member states indeed increases the problems of harmonization between the different systems, the related issues of political distortions and that of the preservation of citizens rights. Schmidtchen, Neunzig and Schmidt-Trenz tell us that the Commission 'seems to take for granted that enlargement enhances the wealth of both the citizens of the EU and the citizens of the applicant countries'. Their chapter stresses the necessity not to jump so directly to optimistic conclusions. As they note, 'there is no free lunch. Increasing membership of a club may come along with congestion and decisionmaking costs'. The problem here is then to determine the optimum size of the European Union. Drawing on the theory of optimal legal areas, Schmidtchen, Neunzig and Schmidt-Trenz propose a model allowing evaluation of who the winners and the losers are from an enlargement of the European Union. Their message is that 'there is no guarantee that what is good for the Union, that is, maximizes Union welfare, is also good for the group as a whole'. To some extent, the impossibility of deriving a definite answer from the comparison between the benefits and the costs of enlargement provides another illustration of the difficulties to positively argue in favour of (spontaneous) harmonization or (conscious) regulation. Once again, decisions about enlargement are likely to remain political choices.

\section{An Efficient Control of the Future European State}

If the future Europe is to be a federation, then the choice of a specific form of federalism requires paying attention to the scope of the power delegated to the central institutions. In the absence of constitutional safeguards, the European federalism would have to be centralized, just as in the USA. In counterpoint, confederations are characterized by the delegation of few, limited and enumerated tasks - as is exemplified by the Articles of Confederation - under the control of the member states. Federalists emphasize the weakness of the central government as a major drawback of this kind of organization; for instance, Hamilton notes that under the Articles 'the government of the United States is destitute of energy' (Federalist Paper 15). A constitution must provide the upper level with prerogatives granting 'the means, and ... methods, of executing the powers with which it is entrusted' (Federalist Paper 16). The need for a central judiciary power is then presented as a necessity in order 'to avoid the confusion which would unavoidably result from the contradictory decisions of a number 
of independent judicatories' (Hamilton, Federalist Paper 22). But, if confederations are sometimes paralysed by the trickiness of their decision processes, the reverse may be sometimes said of federations, which would be granted too many prerogatives. Admittedly, the veto power owned by each state is likely to prevent them from reaching an agreement; on the other hand, the federal court of justice possibly turns out to be a very powerful agent who may well get more power than initially planned by the framers of the constitution. Therefore, constitutional provisions are required to limit the authority of the central government. In the USA, the debates in and around the Convention of Philadelphia clearly revealed concerns shared - to a different extent of course - by both federalists and anti-federalists.

The problem is sharper in Europe since no constituent assembly presides over the making of the constitution: it happens to be the role of the Court itself. The constitutional safeguards required in a federation are still to be designed. First, the European parliament is initially conceived as a consultative structure. Its role has been increased through the introduction (Maastricht treaty) and extension (Treaty of Amsterdam) of the co-decision procedure. The parliament can now balance the power of the Court but its new competencies have mainly resulted from bargaining with the Court and have resulted in an increase of the power of the Court (Cooter and Drexl, 1994; Cooter and Ginsburg, 1999). Second, subsidiarity remains a vague principle. Section two of Article 3B of the Treaty of Maastricht expresses the stretch between the two levels of principalship - the member states on one hand, the citizens on the other - by putting emphasis on the relationship between the member states and the Community. It thus rests on the Court to balance powers by increasingly defending the rights of the other principal, the people of Europe.

Not so surprisingly, the subsidiarity principle protects citizens since it increases their possibilities to sue their own state. There exists another way to protect citizens' rights, namely the delineation of the scope of public utilities. In this perspective, the ECJ also plays a major role. The conventional view, especially in France, is that Europe threatens the French tradition of public utility. In Chapter 5 Thierry Garcia and Xavier Peraldi remind us of a statement of the French Council of State, arguing that 'Europe does not institute proceedings against public utility: it does worse; it unawares the concept of public utility and the existence of public utility'.

However, the problem is not as obvious as it could seem at first sight. Garcia and Peraldi argue in their chapter that, beside 'antagonisms which characterize the French and European approaches of public utility . . ., it is possible to detect a marked phenomenon of convergence'. It is indeed difficult to define a European conception of public utility, the reason being that the ECJ and the Commission do not systematically adopt the same point of view. The Commission uses a restrictive approach, based on the supply of a minimal 
service for a certain level of quality and an accessible price. The Court develops a wider conception, considering the necessity to take into account collective needs (political, social as well as economic). It is then interesting to note that the European Community links the definition of public utility to a principle of European citizenship. Not only does it reinforce the role of the people of Europe as a principal, but it also increases the level of protection of their rights. Thus, to focus on what citizens' rights should be, on the one hand, or to delineate the domain of public utilities, on the other hand, are the two available ways of controlling the State. These two perspectives also relate to the two major traditions that exist in administrative law, whose goal is to control the actions of the state, namely the continental and the British-American traditions. As noted in Chapter 12 Jürgen Backhaus, when presenting the different traditions in administrative law, there exists 'a deep divide separating administrative law'. It is thus said that 'the French approach emphasizes rules, procedures, and clearly circumscribed acts while the British inspired approach tries to structure the discretion of the civil servant by means of general principals that should guide this behaviour'. Furthermore, in the USA, 'the protection of the citizen is mainly contained in the Bill of Rights, administration as a much recent phenomenon has primarily taken on the form of regulation'. The question immediately arising relates to the possibility of creating a common administrative law in Europe. So an important gap between the French-German and the British-US traditions could prevent the emergence of a common administrative law in Europe. One can easily imagine what the practical issues that stand behind the theoretical debate are: Europe was born within the French tradition and evolved under the auspices of the Anglo-Saxon precepts. Once again, if Europe stands in the middle of the ford, the odds are great that the goal of administrative law will not be reached; the European State might remain uncontrolled. Jürgen Backhaus offers an integrative approach in his chapter. He works out the principles of administrative law that 'are in full agreement with economic reasoning, hence they can serve to facilitate the economic analysis of an issue in administrative law'. He then concludes that 'the principles of administrative law, as they embody economic reasoning, can usefully be introduced in arguments of the European Commission in particular and in processes of European harmonization more generally' (emphasis added).

\section{CONCLUSION: TAKING EUROPEAN LAW AND ECONOMICS SERIOUSLY}

This book intends to demonstrate that one cannot understand the making of Europe without taking into account its legal dimension. The debate between 
competition and harmonization will certainly shape the future constitutional moment. In this field, as in many others, law and economics matters.

\section{REFERENCES}

Aghion, Philippe and Jean Tirole (1997), 'Formal and real authority in organizations', Journal of Political Economy, 105(1), 1-29.

Alesina, Alberto and Enrico Spolaore (1997), 'On the number and size of nations', Quarterly Journal of Economics, 112(4), 1027-56.

Anderson, Terry L. and Peter J. Hill (1986), 'Constraining the transfer society: constitutional and moral dimensions', Cato Journal, 6(1), 317-39.

Backhaus, Jürgen G. (1997a), 'Christian Wolff on subsidiarity, the division of labour and social welfare', European Journal of Law and Economics, 4(2-3), 129-46.

Backhaus, Jürgen G. (1997b), 'Subsidiarity and ecologically based taxation: a European constitutional perspective', Public Choice, 90(1-4), 281-310.

Backhaus, Jürgen G. (1999), Subsidiarity, in Jürgen G. Backhaus (ed.), The Elgar Companion to Law and Economics, Aldershot: Edward Elgar, 136-43.

Blum, Ulrich and Leonard Dudley (1991), 'A spatial model of the state', Journal of Institutional and Theoretical Economics, 147(2), 312-36.

Bolton, Patrick and Gérard Roland (1997), 'The break-up of nations: a political economy analysis', Quarterly Journal of Economics, 112(4), 1057-90.

Brennan, Geoffrey and James M. Buchanan (1995), The Reason of Rules. An Essay in Constitutional Political Economy, Cambridge: Cambridge University Press.

Buchanan, James M. (1990), 'The domain of constitutional economics', Constitutional Political Economy, 1(1), 1-18.

Buchanan, James M. (1996), 'Europe as a social reality', Constitutional Political Economy, 7(4), 253-6.

Carney, William J. (1997), 'The political economy of competition for corporate charters', The Journal of Legal Studies, 26(1), 303-29.

Cooter, Robert and Josef Drexl (1994), 'The logic of power in the emerging European constitution: game theory and the division of powers', International Review of Law and Economics, 14(XXX), 307-26.

Cooter, Robert and Tom Ginsburg (1999), 'Division of Powers in the European Constitution', in Peter Newman (ed.), The New Palgrave Dictionary of Economics and the Law.

Darwin, Charles (1859 [1988]), The Origin of Species, London: Encyclopedia Britannica.

Darwin, C. (1871 [1988] ), The Descent of Man and Selection in Relation to Sex, London: Encyclopedia Britannica.

Donahue, John D. (1997), 'Tiebout? Or not Tiebout? The market metaphor and America's devolution debate', Journal of Economic Perspectives, 11(4), 73-81.

Drèze, Jacques (1993), 'Regions of Europe: a feasible status, to be discussed', Economic Policy, 8(17), 265-87.

European Journal of Public Policy (1999), Special issue: 'The social construction of Europe', 6(4), 527-720.

Frey, Bruno S. and Reiner Eichenberger (1996), 'FOCJ: competitive governments for Europe', International Review of Law and Economics, 16(3), 315-27.

Frey, Bruno S. and Reiner Eichenberger (1997), 'FOCJ: Creating a Single European 
Market for Governments', in Dieter Schmidtchen and Roger Cooter (eds), Constitutional Law and the European Union, Aldershot: Edward Elgar.

Hayek, Friedrich August (1988), The Fatal Conceit. The Errors of Socialism, Chicago: University of Chicago Press.

Hogue, Arthur (1966), The Origins of the Common Law, Indianapolis: The Free Press.

Holcombe, Randall (1991), 'Constitutions as constraints: a case-study of three American constitutions', Constitutional Political Economy, 2(3), 303-28.

Inman, Robert P. and Daniel L. Rubinfeld (1996), 'Designing tax policy in federalist economies', Journal of Public Economics, 60(3), 307-34.

Inman, Robert P. and Daniel L. Rubinfeld (1997a), 'Rethinking federalism', Journal of Economic Perspectives, 11(4), 43-64.

Inman, Robert P. and Daniel L. Rubinfeld (1997b), 'The Political Economy of Federalism', in Dennis C. Mueller (ed.), Perspectives on Public Choice, Cambridge: Cambridge University Press, pp. 73-105.

Josselin, Jean-Michel and Alain Marciano (1995), 'Constitutionalism and common knowledge: assessment and application to a future European constitution', Public Choice, 85(1-2), 173-88.

Josselin, Jean-Michel and Alain Marciano (1997), 'The paradox of Leviathan: how to develop and contain the future European state', European Journal of Law and Economics, 4(1), 5-21.

Josselin, Jean-Michel and Alain Marciano (1999a), 'Administrative Law and Economics', in Jürgen G. Backhaus (ed.), The Elgar Companion to Law and Economics, Aldershot: Edward Elgar, pp. 115-20.

Josselin, Jean-Michel and Alain Marciano (1996b), 'General Norms and Customs', in Jürgen G. Backhaus (ed.), The Elgar Companion to Law and Economics, Aldershot: Edward Elgar, pp. 233-9.

Josselin, Jean-Michel and Alain Marciano (1999c), 'Unitary states and peripheral regions: A model of heterogeneous spatial clubs', International Review of Law and Economics, 19(4), 501-11.

Josselin, Jean-Michel and Alain Marciano (2000), 'Displacing your principal. Two historical case studies of some interest for the constitutional future of Europe', European Journal of Law and Economics, 10(3), 217-33.

Josselin, Jean-Michel and Alain Marciano (2001), 'Public decisions in the Scottish Enlightenment tradition', Journal of Economic Studies, 27(6), 5-13.

Koslowsky, Rey (1999), 'A constructivist approach to understanding the European Union as a federal polity', Journal of European Public Policy, 6(4), 561-78.

Marciano, Alain and Maud Pélissier (2000), 'The influence of Scottish enlightenment on Darwin's theory of cultural evolution', Journal of the History of Economic Thought, 22(2), 239-49.

Mercuro, Nicholas and Steve G. Medema (1997), Economics and the Law. From Posner to Post-Modernism, Princeton: Princeton University Press.

Musgrave, Richard A. (1997), 'Devolution, grants, and fiscal competition', Journal of Economic Perspectives, 11(4), 65-72.

Nozick, Robert (1974), Anarchy, State and Utopia, New York: Basic Books.

Rose-Ackerman, Susan (1992), Re-thinking the Progressive Agenda, the Reform of the American Regulatory State, New York: The Free Press.

Salmon, Pierre (1987), 'Decentralisation as an incentive scheme', Oxford Review of Economic Policy, 3(2), 24-43.

Salmon, Pierre (2000), 'Vertical Competition in a Unitary State', in G. Galeotti, P. Salmon and R. Wintrobe (eds), Competition and Structure. The Political Economy 
of Collective Decisions: Essays in Honor of Albert Breton, Cambridge: Cambridge University Press, pp. 239-56.

Sbraggia, A.M. (1992), 'Thinking about the European Future: The Uses of Comparison', in A.M. Sbraggia (ed.), Euro-Politics. Institutions and Policy Making in the 'New' European Community, Washington, DC: Brooking Institution.

Schilling, Theodor (1996), 'The autonomy of the community legal order: an analysis of possible foundations', Harvard International Law Journal, 37.

Scott, Anthony (2000), 'Assigning Powers Over the Canadian Environment', in G. Galeotti, P. Salmon and R. Wintrobe (eds), Competition and Structure. The Political Economy of Collective Decisions: Essays in Honor of Albert Breton, Cambridge: Cambridge University Press, pp. 174-219.

Tannenwald, Robert (1998), 'Devolution: The new federalism - An overview', Federal Reserve Bank of Boston - New England Economic Review, May/June, 1-12.

Van den Bergh, Roger (1994), 'The subsidiarity principle in European Community law: some insights from law and economics', Maastricht Journal of European and Comparative Law, 337-66.

Van den Bergh, Roger, Michael Faure and Jürgen Lefevere (1995), 'The Subsidiarity Principle in European Environmental Law: An Economic Analysis', in E. Eide and R. van den Bergh (eds), Law and Economics of the Environment, Oslo: Juridisk Forlag: 121-66.

Vibert, Frank (1995), Europe, A Constitution for the Millennium, Aldershot: Dartmouth.

Wagner, Richard E. (1988), 'Agency, Economic Calculation and Constitutional Construction', in Charles K. Rowley, Robert D. Tollison and Gordon Tullock (eds), The Political Economy of Rent-Seeking, Boston: Kluwer, pp. 423-45.

Wagner, Richard E. (1993), Parchment, Guns and the Maintenance of Constitutional Contract, Shaftesbury Papers 3, Aldershot: Edward Elgar.

Weiler, Joseph H. and Ulrich R. Halpern (1996), 'The autonomy of the community legal order. Through the looking glass', Working Paper, Harvard Law School.

Wittman, Donald (1991), 'Nations and states: mergers and acquisitions, dissolution and divorce', American Economic Review, 81(2), 126-9. 
Jean-Michel Josselin and Alain Marciano - 9781781950692 Downloaded from PubFactory at 04/26/2023 12:20:26PM via free access 